\title{
Study of maternal and fetal outcome in twin pregnancy
}

\author{
Lata Singh*, Kiran Trivedi
}

Department of Obstetrics and Gynecology, Rajendra Institute of Medical Sciences, Ranchi, Jharkhand, India

Received: 25 April 2017

Accepted: 01 May 2017

\section{*Correspondence:}

Dr. Lata Singh,

E-mail: latarsingh13@gmail.com

Copyright: ( ) the author(s), publisher and licensee Medip Academy. This is an open-access article distributed under the terms of the Creative Commons Attribution Non-Commercial License, which permits unrestricted non-commercial use, distribution, and reproduction in any medium, provided the original work is properly cited.

\section{ABSTRACT}

Background: Multiple pregnancies are associated with an increased risk of obstetric complications as well as perinatal morbidity and mortality especially in developing countries. The present study aims to understand the maternal and perinatal outcomes of multiple and singleton pregnancies delivering at Rajendra Institute of Medical Sciences, Ranchi, India. Aim of study was to investigate the maternal and fetal outcome in twin pregnancies in Rajendra Institute of Medical Sciences (RIMS), Ranchi

Methods: This comparative prospective study was conducted in the department of obstetrics and gynecology, Rajendra Institute of Medical Sciences, Ranchi from the period of $1^{\text {st }}$ April 2015 to $30^{\text {th }}$ September 2016. Consecutive sampling was done till the sample size of 75 was reached for both twin and singleton pregnancies. It included all women admitted in antenatal ward and labor room with clinical or ultrasound diagnosis of twin pregnancy after 28 weeks of gestation.

Results: The incidence of twins in this study was $1.85 \%$. Mean maternal age was $25.25 \pm 4.5$ years for twin pregnancies and $23.53 \pm 3.3$ for singleton pregnancies. Twins were seen more in multigravida (70.7\%) as compared to primigravida (29.3\%). Preterm labor (74.7\%), anemia (44\%) and hypertensive disorders (32\%) and PPH (13.33\%) were the most common complication in twin pregnancies. Significantly higher rate of LSCS were seen in twin pregnancies $(32.67 \%$ ) as compared to singletons $18.67 \%$. Mean weight of first twin was $2.03 \pm 0.52 \mathrm{~kg}$ and for second twin it was $1.98 \pm 0.51 \mathrm{~kg}$. There was higher incidence of moderate to severe asphyxia, IUGR and higher rate of NICU admissions in twins as compared to singletons. Perinatal mortality rate of monchrionic pregnancy was $30 \%$ and it was $10.2 \%$ for dichorionic pregnancy which shows a significant association of perinatal mortality rate and chorionicity.

Conclusions: Good antenatal care, with increased rest and nutritional supplementation, early detection of fetal and maternal complications together with thorough intranatal and postnatal vigilance, can lower both maternal and fetal dangers.

Keywords: Fetal outcome, Maternal outcome, Singleton pregnancy, Twin pregnancy

\section{INTRODUCTION}

Multiple gestations are becoming a problem of increasing dimensions with the dramatic increase in numbers due to a trend towards late childbearing and the widespread use of assisted reproduction. The Worldwide incidence of multiple pregnancies varies considerably it is around 2 20 per 1000 births. $^{1}$ Highest burden of multiple pregnancies has been found in Sub-Saharan Africa, with an average twinning rate of 20 per 1,000 deliveries compared to 10 per 1,000 deliveries in Europe and around 5-6 per 1,000 deliveries in Asia. ${ }^{2-4}$

The number and rate of twin, triplet and higher order multiple births have also increased in India at an unprecedented pace over the past two decades. This 
extraordinary increase in multiple births is a public health hazard because such pregnancies are associated with increased risk for both mother and the child. It poses on the new-born, the risk of reduced survival and lifelong disability because of high rate of preterm birth. Risk increases with the number of off springs.

Compared to singleton pregnancies, multiple pregnancies are reported to carry higher maternal as well as perinatal morbidity and mortality. ${ }^{5-6}$ The various complications encountered in mothers are anaemia, hyperemesis, preterm labour, hypertensive disorders of pregnancy, antepartum haemorrhage, polyhydramnios, increased pressure symptoms, varicose veins and gestational diabetes. Low birth weight, contributed by both prematurity and IUGR, is the main factor responsible for higher perinatal mortality in twins. Major priorities in the management of twin gestations are early and accurate prenatal diagnosis, detection and management of maternal complications and foetal growth restriction. Planning the time and mode of delivery in complicated twin pregnancies and early detection of monochorionic placentation and managing its consequences are crucial steps leading to a higher probability of successful outcome. Objective was to study the maternal and fetal outcome in twin pregnancies in Rajendra Institute of Medical Sciences (RIMS), Ranchi.

\section{METHODS}

This comparative prospective study was conducted in the department of obstetrics and gynecology, Rajendra Institute of Medical Sciences, Ranchi from the period of $1^{\text {st }}$ April 2015 to $30^{\text {th }}$ September 2016. Consecutive sampling was done till the sample size of 75 was reached for both twin and singleton pregnancies. It included all women admitted in antenatal ward and labor room with clinical or ultrasound diagnosis of twin pregnancy after 28 weeks of gestation. For each twin gestation, next singleton pregnancy was admitted being taken as controls. They were followed from admission through delivery up to discharge of both mother and baby from the hospital. A pretested semi structured proforma was used for data collection. Data related to maternal age, parity, socioeconomic status, maternal medical and obstetrical complications, ultrasonography for chorionicity, fetal viability, malformations, evidence of abnormal vascular communications and presentation of both the fetuses was collected in the proforma. The mode of delivery, intrapartum and postpartum complications, requirement of blood transfusion, neonatal outcome in terms of birth weight, APGAR score, NICU admissions and perinatal death was taken into account. Examination of placenta was done to confirm the chorionicity. Gestational age was calculated from LMP and the date of delivery in completed weeks after LMP. Socioeconomic status was derived by Kuppuswamy scale. Patients with three or more antenatal visits were considered booked. IUGR was determined by birth weight below 2 SD of mean birth weight for each gestational age. Birth asphyxia was indexed by APGAR score $<7$ at 5 minutes of birth. Low birth weight was taken as $<2.5 \mathrm{~kg}$ and preterm $<37$ completed weeks.

\section{Statistical analysis}

Data entries for both, cases and controls were done using Microsoft excel 2007 and analyzed using SPSS 2016. To compare the significance of difference in perinatal and maternal outcomes, Pearson's chi square test, Fisher's exact test and independent sample $t$ test was used. 5\% confidence interval was considered for this study.

\section{RESULTS}

During the study period of 18 months there were 9843 deliveries including 179 twin deliveries, giving the incidence of twin $1.85 \%$. The distribution of twin in relation to maternal socio demographic profile is shown in Table 1 .

Table 1: Socio demographic and obstetrical profile of patients under study.

\begin{tabular}{|llll|} 
& & Twin pregnancies & Singleton pregnancies \\
Mean age & In years & $25.25 \pm 4.532$ & $23.53 \pm 3.375$ \\
\hline \multirow{2}{*}{$\begin{array}{l}\text { Socio economic } \\
\text { status }\end{array}$} & Lower & $43(57.33 \%)$ & $45(60.00 \%)$ \\
\cline { 2 - 4 } Antenatal visits & Middle & $27(36.00 \%)$ & $23(30.67 \%)$ \\
\cline { 2 - 3 } & Upper & $5(6.67 \%)$ & $7(9.33 \%)$ \\
\hline \multirow{2}{*}{ Gravida } & Booked & $38(50.67 \%)$ & $36(48.00 \%)$ \\
\cline { 2 - 4 } & Unbooked & $37(49.33 \%)$ & $39(52.00 \%)$ \\
\hline
\end{tabular}

Maximum number of women in both the groups, twin and singletons were of 21-26 years of age, but as the maternal age increased (>30 years) more number of cases were seen in twin pregnancy $(20.0 \%)$ as compared to singleton 
pregnancies $(6.7 \%)$. Also, the mean maternal age was $25.25 \pm 4.5$ years for twin pregnancies and 23.53 \pm 3.3 for singleton pregnancies. Most of the patients in both the groups belonged to low economic status. In both the groups almost equal number of patients were booked, as were unbooked. Twins were seen more in multigravida (70.7\%) as compared to primigravida (29.3\%). In singletons $45.3 \%$ patients were primigravida and $59.7 \%$ were multigravida (chi square $4.1032 \mathrm{p}$ value 0.0427 ).

Table 2: Maternal complications.

\begin{tabular}{|c|c|c|c|c|c|c|}
\hline \multirow{2}{*}{ Complications } & \multicolumn{2}{|c|}{ Twin pregnancy } & \multicolumn{2}{|c|}{ Singleton pregnancy } & \multirow{2}{*}{ Chi square } & \multirow{2}{*}{ P value } \\
\hline & No. of cases & $\%$ & No. of cases & $\%$ & & \\
\hline Preterm Labour & 56 & 74.7 & 19 & 25.3 & 36.507 & $<0.0001$ \\
\hline Anaemia & 33 & 44 & 16 & 21.33 & 8.75 & 0.003 \\
\hline $\begin{array}{l}\text { Hypertensive disorders of } \\
\text { pregnancy }\end{array}$ & 24 & 32 & 13 & 17.33 & 4.3411 & 0.037 \\
\hline Antepartum haemorrhage & 3 & 4 & 3 & 4 & - & - \\
\hline PROM & 8 & 10.67 & 4 & 5.33 & - & - \\
\hline PPH & 10 & 13.33 & 6 & 8 & 1.1194 & 0.2900 \\
\hline Requirement of BT & 30 & 40 & 12 & 16 & 10.714 & 0.001 \\
\hline LSCS & 49 & 32.67 & 14 & 18.67 & 4.1927 & 0.040 \\
\hline
\end{tabular}

Table 2 shows major complications developing in mothers in antenatal and intrapartum period. $74.7 \%$ of women among twin pregnancies delivered preterm and $25.3 \%$ among singleton pregnancies delivered preterm (chi square 36.507 , degree of freedom $(\mathrm{df}=1)$, p value $<0.0001)$. Mean gestational age of delivery in cases was $33.48 \pm 3.32$ weeks and in controls it was $37.43 \pm 3.79$ weeks (Chi square $36.507(\mathrm{df}=1)$ and $\mathrm{p}$ value $<0.0001)$. Anemia was the commonest medical disorder in twin pregnancies (44\%) and $21.33 \%$ in singletons. Hypertensive disorder in pregnancy is the next in order, $32 \%$ in twin gestations as compared to $17.33 \%$ in singleton pregnancies (Table 2). In this study, no difference was seen in the incidence of APH between the two study groups (1.33\% in both the groups). PROM was found in 8 cases $(10.67 \%)$ as compared to controls 4 $(5.33 \%)$. Significantly higher rate of LSCS were seen in twin pregnancies $(32.67 \%)$ as compared to singletons $18.67 \%$ (chi sq. $4.1927 \quad(\mathrm{df}=1), \mathrm{p}$ value 0.040).
Spontaneous vaginal delivery was seen in $62.67 \%$ of twins and $77.3 \%$ of singletons. Assisted vaginal delivery with forceps vector was required in $4.67 \%$ of twins and $4 \%$ of singletons. Mode of delivery however was not found to affect the perinatal mortality. PPH was seen in $13.33 \%$ of twin pregnancies and $8 \%$ cases of singleton pregnancies (not statistically significant with $\mathrm{p}$ value).

There was one case of retained placenta, 2 cases of cord prolapse in twins. None of the twins were into obstruction. BT was required in $40 \%$ of twin pregnancies as compared to $16 \%$ of singleton pregnancies.

\section{Perinatal outcome}

Table 3 shows the perinatal outcome in twins as well as singletons. Maximum percentage of twins had birth weight between $1.5 \mathrm{~kg}-2 \mathrm{Kg}$. Mean weight of first twin was $2.03 \pm 0.52 \mathrm{~kg}$ and for second twin it was $1.98 \pm 0.51 \mathrm{~kg}$.

Table 3: Perinatal outcome with significant difference between the two groups.

\begin{tabular}{|c|c|c|c|c|}
\hline Variable & & Twins; Mean/Number (\%) & Singletons; Mean/Number (\%) & $\chi^{2}$ (P-value) \\
\hline Mean Birth weight & & 1.95 & 2.70 & $(<0.0001)$ \\
\hline \multirow{2}{*}{ Prematurity } & Yes & $112(74.67 \%)$ & $19(25.33 \%)$ & $\chi^{2}=50.02$ \\
\hline & No & $38(25.33 \%)$ & $56(74.67 \%)$ & $(<0.0001)$ \\
\hline \multirow{2}{*}{ IUGR } & Yes & $38(9.5)$ & $55(27.2)$ & $\chi^{2}=32.29$ \\
\hline & No & $362(90.5)$ & $147(72.8)$ & $(<0.001)$ \\
\hline \multirow{2}{*}{ APGAR(5min) } & $<7$ & $29(20.42)$ & $6(8.33)$ & $\chi^{2}=0.8172$ \\
\hline & $>7$ & $112(78.87)$ & $66(91.67)$ & $(0.360)$ \\
\hline \multirow{2}{*}{ NICU Admissions } & Yes & $38(26.76)$ & $10(13.89)$ & $\chi^{2}=4.5494$ \\
\hline & No & $104(73.23)$ & $62(86.11)$ & $(0.032)$ \\
\hline \multirow{2}{*}{ Perinatal death } & Yes & $27(18 \%)$ & $6(8 \%)$ & $\chi^{2}=3.9950$ \\
\hline & No & $123(82 \%)$ & $69(92 \%)$ & $(0.0456)$ \\
\hline
\end{tabular}




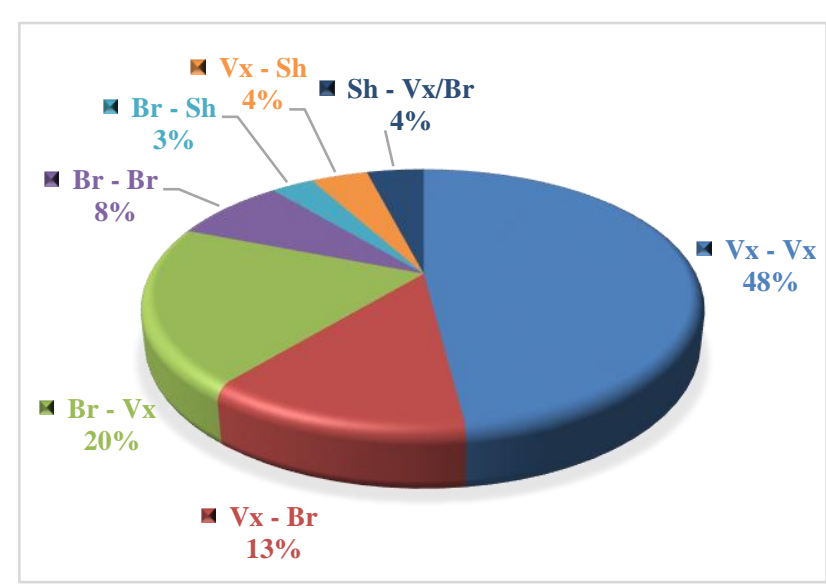

Vx- Vertex, Br- Breech, Sh- Shoulder

Figure 1: Presentation of both babies in twin pregnancy.

For singletons mean weight was $2.70 \pm 0.81 \mathrm{~kg}$. IUGR was seen in $24 \%$ of twins as compared to $12 \%$ of singletons (chi square $4.5(\mathrm{df}=1) \mathrm{p}$ value 0.033$)$. There was higher incidence of moderate to severe asphyxia in twins as compared to singletons. Higher rate of NICU admissions were seen in twins $(34.67 \%)$ as compared $18.67 \%$ in singletons (chi square $6.5750(\mathrm{df}=1) \mathrm{p}$ value 0.028$)$. Very high perinatal mortality was observed in twins, 27 out of $150(18 \%)$ and in singletons, it was $6(8 \%)$. Early neonatal death accounted more than still births to the total perinatal mortality in twins. The difference between both the groups were statistically significant (chi square 3.5290, $(\mathrm{df}=1) \mathrm{p}$ value 0.025$)$. Most of the babies $(56.20 \%)$ who were lost, weighed $<1.5 \mathrm{~kg}$ irrespective of gestational age. Most common presentation was vertex for both the twins (48\%) followed by 1st breech second vertex $(20 \%)$.

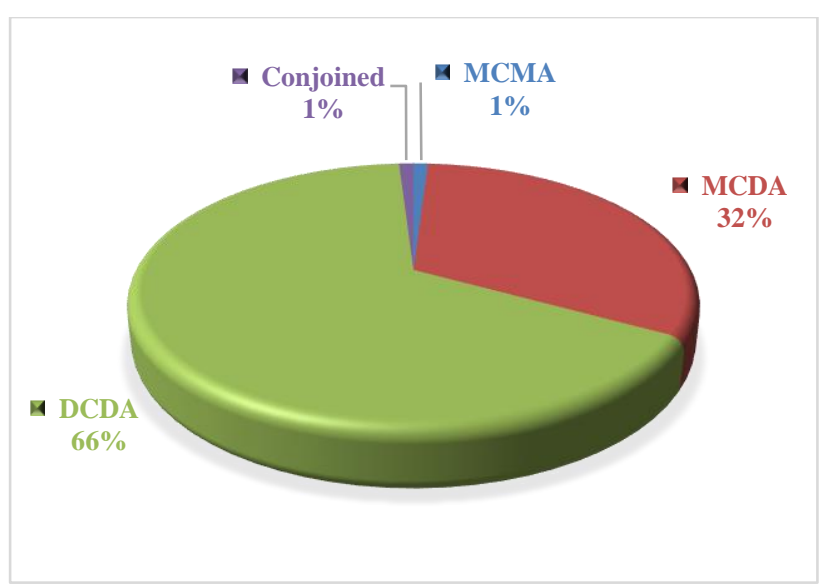

MCMA-monochorionic monoamniotic, MCDA-monochorionic diamniotic, DCDA-dichorionic diamniotic

Figure 2: Chorionicity.

Next in order was $1^{\text {st }}$ vertex and $2^{\text {nd }}$ breech $(13.33 \%)$ and both breech $(8 \%)$. Those with shoulder presentation were few (Figure 1). Non- vertex presentation was associated with higher perinatal mortality rates than vertex presentations (chi square $4.34(\mathrm{df}=1) \mathrm{p}$ value 0.0375). Second twin had a slightly higher mortality rate compared to first twin. No significant difference was seen in mortality rate, when the delivery interval between twins was increased.

Most of twins were diamniotic dichorionic (65\%). There was one case of monoamniotic monochorionic pregnancy and one case of conjoined twin (Figure 2). Perinatal mortality rate of monchorionic pregnancy was $30 \%$ and it was $10.2 \%$ for dichorionic pregnancy which shows a significant association of perinatal mortality rate and chronicity (chi square 10.167 ( $\mathrm{df}=1$ ) p value 0.0017 ).

Table 4: Relation of chorionicity and perinatal mortality.

\begin{tabular}{|c|c|c|c|c|c|c|c|c|}
\hline \multirow{2}{*}{$\begin{array}{l}\text { Type of } \\
\text { placenta }\end{array}$} & \multicolumn{2}{|c|}{$1^{\text {st }}$ twin } & \multicolumn{2}{|c|}{$2^{\text {nd }}$ twin } & \multicolumn{2}{|c|}{ Total } & \multirow{2}{*}{$\begin{array}{l}\text { Chi } \\
\text { square }\end{array}$} & \multirow{2}{*}{$P$ value } \\
\hline & No. & PNM & No. & PNM & No. & PNM & & \\
\hline MCMA & 1 & $1(100 \%)$ & 1 & $1(100 \%)$ & 2 & $2(100 \%)$ & \multirow{4}{*}{10.167} & \multirow{4}{*}{0.0014} \\
\hline MCDA & 24 & $4(16.67 \%)$ & 24 & $9(37.5 \%)$ & 48 & $13(27.08 \%)$ & & \\
\hline DCDA & 49 & $5(10.20 \%)$ & 49 & $5(10.2 \%)$ & 98 & $10(10.20 \%)$ & & \\
\hline Conjoined & 1 & $1(100 \%)$ & 1 & $1(100 \%)$ & 2 & $2(100 \%)$ & & \\
\hline
\end{tabular}

\section{DISCUSSION}

Incidence of twins in this study was $(1.81 \%)$ which is much higher than the incidence of twins in India which is around $0.9 \%-1 \%$ obtained for various studies. This may be because our institution being the only tertiary centre, in the state has referrals from most of the peripheral hospitals in Jharkhand. Also, twin pregnancies with complications are referred from many private hospitals for better management. Comparable incidence was seen in studies done by Bangal et al (1.49\%) and a study done in Sheikh Muji Medical University, Dhaka.,

Mean gestational age in both the groups was 21-26 years. Similar findings were obtained by Bangal et al where majority of women were in age group 20-30 years which is the peak reproductive age group. ${ }^{7}$ Incidence of twin pregnancy is higher in multigravida $(70.7 \%)$ as compared to primigravida. Similar findings were obtained by Chowdhury who reported the order of twin multigravida 
(64.2\%) as compared to primigravida $(35.5 \%){ }^{8}$ Preterm labor was the most common obstetrical complication among twin gestation. Anemia followed next in order by Hypertensive disorders in pregnancy, were the two most common medical complications in twin pregnancy. Preterm delivery occurred in 56 out of 75 cases of twins accounting for $74.7 \%$ cases. In singletons, $19 \%$ of woman had preterm deliveries. Mean gestational age in twin pregnancy group was 33.48 weeks \pm 3.32 weeks while in singleton pregnancies it was 37.48 weeks \pm 3.79 weeks.

The incidence of preterm labor in present study was somewhere in between $(74.7 \%)$ that found by two researchers, Bangal et al and Chowdhury et al. ${ }^{7,8}$ The incidence of preterm delivery was high $(88 \%)$ in the study done by Bangal et al and it was (44\%) as reported by Chowdhury et al. In Australia in 2009 (Australia's Mothers and Babies, AIHW, 2011) the overall rate of preterm birth (birth before 37 weeks) amongst women with twins was $52.2 \% .^{9}$

In our study, Anemia was found in 33 twin pregnancies (44\%) and 16 singleton pregnancies (21.33\%) The difference in two groups was found significant with chi square $8.75(\mathrm{df}=2)$ and $\mathrm{p}$ value 0.003 . A very high incidence of anaemia was found by Bangal et al (84\%) in 2012.The corresponding figures reported by Chowdhury were $35.8 \%$ for anaemia cases. Similar findings were observed by Brown et al $(35.5 \%)$ of patients as anaemic in twin gestations. ${ }^{10}$ The prevalence of anaemia varies from place to place, but in all the above-mentioned studies, incidence was more in twin gestations as compared to singleton gestations. The main reason is higher demand in twin gestations resulting in iron, Vitamin B12 and folic acid deficiency anemia.

In the present study, hypertensive disorders were common in twin than singleton pregnancies. Incidence of hypertensive disorders in twin pregnancies was $32 \%$. Out of which, gestational hypertension comprised 7\%, preeclampsia $11 \%$ and eclampsia $6 \%$ of patients. While in singleton pregnancies, incidence of hypertensive disorders was $17.33 \%$, of which gestational hypertension and preeclampsia each was seen in $6.67 \%$ and eclampsia in $4 \%$ patients. High incidence of Pregnancy Induced Hypertension was also observed by Bangal et al as $18 \%$ and by Chowdhury et al who reported incidence of $22.6 \%$ for hypertension cases in twin gestations. ${ }^{7,8}$ The large placenta in multiple pregnancies probably exposes mothers to more paternal antigen and placental secreted pregnancy hormones which are likely to contribute to pre-eclampsia and eclampsia in twin pregnancies.

In this study no difference was seen in the incidence of APH between the two study groups (1.33\% in both the groups). Similar incidence of APH was seen (2\%) by Yuel Veronica et al. ${ }^{11}$ This was contrary to findings of many researchers who have found significant association between APH and twin pregnancies. Incidence of PROM in this study was $10.67 \%$ in twin pregnancies (8 cases and $5.33 \%$ in singleton controls (4 patients). Similar incidence of PROM in twin gestations $(10 \%)$ was seen by Mahita et al. ${ }^{12}$

In this study, Hydramnios has been recorded in 8 twin pregnancies (10.67\%). Hydramnios was seen in $12 \%$ cases of twin gestations by Bangal et al which is very similar to the incidence of Hydramnios in present study $(10.67 \%){ }^{7}$ Chowdhury et al reported incidence of $5.7 \%$ for polyhydramnios in twin gestations. ${ }^{8}$ Incidence of $\mathrm{PPH}$ among twin gestation was $10(13.33 \%)$ and that among singleton gestation was $6(8 \%)$. Many studies have shown similar results, Stock $\mathrm{S}$ and Norman J Latin America and Singhakun D Thailand with increased rate of occurrence of PPH in twin pregnancies. ${ }^{13,14}$ There was significant difference in the requirement of blood transfusion in twin gestations (40\% cases) as compared to singleton gestations $(16 \%) \mathrm{p}$ value 0.001 . This increased incidence of BT could be explained by significantly high incidence of anaemia and PPH in cases as compared to controls.

Low Birth Weight (LBW) that is birth weight less than $2.5 \mathrm{~kg}$ was seen in 60 out of 75 first baby of twins $(80 \%)$ and 58 out of 75 second baby of twins (77.33\%). Taken together for both babies, LBW was seen in $78.67 \%$ twins. In singletons, LBW was seen in 29 babies $(38.67 \%)$. The difference between both these groups was statistically significant. Very similar incidence of LBW was quoted by Bangal et al. ${ }^{7}$ The incidence of having a baby with a low birth weight (less than 2500 grams) was $82 \%$ in their study. A lower incidence than my study of LBW was reported to be $(51.3 \%)$ by Australia's Mothers and Babies, AIHW for twin pregnancies. ${ }^{9}$ This may be in part due to poor nutritional status of patients in this area and high incidence of IUGR. In current study, $24 \%$ of twins and $12 \%$ of singletons were IUGR. This association of IUGR with twin pregnancy is found statistically significant with chi square $4.5000 \quad(\mathrm{df}=1)$ and $\mathrm{p}$ value $=0.033$.

NICU admissions were required for 52 babies among twins (34.67\%) against 10 (18.67\%) singleton babies, p value 0.0129 indicating high morbidity among twin babies. First baby of twin required NICU admission in 22 out of 75 cases $(29.33 \%)$ and second baby required the same in 30 cases out of $75(40 \%)$. Most common cause of NICU admissions was prematurity and LBW. Higher rate of NICU admissions in $2^{\text {nd }}$ twin was mainly due to greater presence of birth asphyxia in them. This was comparable to the study done in Kerala by Radhakrishnan $\mathrm{R}$ et al, in which NICU admission was required in $28.5 \%$ of $2^{\text {nd }}$ twin compared to $23 \%$ of $1^{\text {st }}$ twin. $^{15}$

The perinatal mortality in twins in present study was $18 \%$ as compared to $8 \%$ in singletons. Neonatal deaths were higher than still births in twins, implicating prematurity as a major cause of perinatal mortality of twins. For first twin baby, perinatal mortality was $14.67 \%$ and that in the second baby was $21.33 \%$. Besides prematurity and low 
birth, which largely accounted for high perinatal mortality of twins, malpresentation added to the higher mortality of second twin. The higher perinatal mortality observed in this study among twin deliveries compared with singletons probably signified the overall hazard accompanying twin deliveries. Similar result was observed by Bangal et al $17.5 \%$ perinatal deaths in 100 twin pregnancies. ${ }^{7}$ Most of the deaths were in babies weighing less than $1.5 \mathrm{Kg}(58.06 \%)$ and higher survival rates were seen as the birth weight increased. Perinatal loss was $6.52 \%$ in birth weight $2.01-2.5 \mathrm{~kg}$ and there were no deaths above $2.5 \mathrm{~kg}$. In singleton controls, all deaths were confined to babies weighing less than 2.5 $\mathrm{Kg}$, with maximum deaths occurring between $1.51-2 \mathrm{~kg}$ group $(42.85 \%)$. Similarly, Mahita Reddy et al found highest perinatal mortality in birth weight of $1-1.5 \mathrm{~kg}$ and highest survival in $>2.5 \mathrm{~kg}$ weight. ${ }^{12}$

The rate of cesarean section in the delivery of twin pregnancies was statistically higher than that in singleton pregnancies $(32.67 \%$ versus $18.67 \%)$. This is in corroboration with Bangal et al who reported the caesarean section rate to be $33 \% .^{7}$ The increase in the use of cesarean section to deliver twin pregnancies may be due to increased incidence of other obstetric indications for cesarean deliveries such as hypertensive disorders, malpresentation, cord prolapse, and premature rupture of membranes as observed in this study. Mode of delivery was not associated with any difference in outcome. In present study it was found that non vertex presentations were associated with higher mortality rates than vertex presentations. Chi square $4.329(\mathrm{df}=1)$ and $\mathrm{p}$ value 0.0375 .

Table 5 shows that $65 \%$ were diamniotic dichorionic. Monochorionic monoamniotic type constituted $32 \%$. There was one case of monochorionic monoamniotic twin pregnancy complicated by hydramnios and intrauterine death of one fetus. There was one conjoined twin (parapagus diprosopus) who died immediately after birth.

This was comparable to a study done in Kerala by Radhakrishnan $\mathrm{R}$ et al who found that 62 percent of the cases were dichorionic diamniotic pregnancy, $37 \%$ mono-chorionic diamniotic pregnancy. ${ }^{15}$ Perinatal mortality rate of monochorionic pregnancy was, $180 / 1000$ (18\%) compared to $60.5 / 1000$ (6\%) for dichorionic pregnancy, which showed a significant association of perinatal mortality and chorionicity. We found that perinatal outcome of twins is influenced by the type of placentation. In present study, perinatal mortality rate of monochorionic pregnancy was $30 \%$, and it was $10.2 \%$ for dichorionic pregnancy, which shows a significant association of perinatal mortality and chronicity (Chi-square 10.167 and p-value 0.0014). Similar data was found in a study of retrospective analysis of 261 twin pregnancies conducted by Mahmut et al where the incidence of dichorionicity was $69.3 \%$ and monochorionicity was $30.7 \% .^{12}$

\section{CONCLUSION}

Multiple pregnancies bear additional hazards both for the mother and the baby. Though these hazards are partly preventable, difficulty in timely recognition of multiple pregnancies at an early date is a main obstacle. Diagnosis of twin pregnancy and determination of chorionicity is essential to anticipate abnormalities of monochorionicity. Antenatal care, with increased rest and nutritional supplementation, early detection of foetal and maternal complications together with thorough intranatal and postnatal vigilance, has much to its credit in lowering both maternal and foetal dangers.

LBW mainly due to preterm labour and intra uterine growth retardation were the most important factors responsible for the neonatal deaths. The perinatal mortality could be reduced considerably if we can achieve birth weight of more than $1.5 \mathrm{~kg}$ in twins. Thus, proper antenatal care, planned delivery and better facilities for care of premature babies can bring about a reduction in perinatal mortality of twin pregnancies.

\section{ACKNOWLEDGMENTS}

Authors would like to thank all the colleagues from Rajendra Institute of Medical Sciences, who provided insight and expertise that greatly assisted the research. Authors would like to show gratitude to Dr. Jacinta Minz (RIMS), Dr. B. Moitra (RIMS) for sharing their pearls of wisdom with us during the course of this research and thank them for assistance and comments that greatly improved the manuscript.

\section{Funding: No funding sources}

Conflict of interest: None declared

Ethical approval: The study was approved by the Institutional Ethics Committee

\section{REFERENCES}

1. Doris MC. Multiple pregnancy. Baillieres Clin Obstet Gynaecol. 1990;4:109-27.

2. Bortolus R, Parazzini F, Chatenoud L, Benzi G, Bianchi MM, Marini A, The epidemiology of multiple births. Hum Reprod Update. 1999;5(2):17987.

3. Goetghebuer T, Ota MO, Kebbeh B, John M, Jackson Sillah D, Vekemans J et al. Delay in motor development of twins in Africa: a prospective cohort study. Twin Res. 2003;6(4):279-84.

4. Hoekstra C, Zhao ZZ, Lambalk CB, Willemsen G, Martin NG, Boomsma DI et al. Dizygotic twinning. Hum Reprod Update. 2008;14(1):37-47.

5. Minakami H, Sato I. Re-estimating date of delivery in multifetal pregnancies. JAMA. 1996;275(18):1432-4.

6. Ashworth MF, Spooner SF, Verky DA, Waterman R, Ashurst HM. Failure to prevent preterm labour and delivery in twin pregnancy using prophylactic oral 
salbutamol. Br J Obstet Gynaecol. 1990;97(10):87882.

7. Bangal VB, Patel SM, Khairnar DN. Study of maternal and foetal outcome in twin gestation at tertiary care teaching hospital. IJBAR. 2012;3(10):758.

8. Chowdhury S, Hussain MA. Maternal complications in twin pregnancies. MMJ. 2011;20(1):83-7.

9. Australia's Mothers and Babies, AIHW, 2011. Perinatal statistics series no. 25 Dec11. Australian Institute of Health and Welfare Canberra. Cat no. PER 52

10. Brown EJ, Dixon HG. Twin pregnancy. J Obstet Gynaecol Br Common. 1963;70:251.

11. Irene YV, Kaur V. An analytical study of pregnancy outcome in multifetal gestation. J Obstet Gynecol India. 2007;57(6):509-12.

12. Reddy MA, Madhavi KSS, Niharica. A study on risk of twin pregnancy. IAIM. 2016;3(10):139-45.
13. Stock S, Norman J. Preterm and term labour in multiple pregnancies. Semin Foetal Neonatal Med. 2010;15(6):336-41.

14. Singhakun D, Israngura N, Ayudhya N. Pregnancy outcome of twin pregnancy in ramathibodi hospital. Med Assoc Thailand. 2006.89(4):76-80.

15. Radhakrishnan R, Radhakrishnan R. Perinatal outcome of twin pregnancy and influence of chorionicity on it. Int $\mathbf{J}$ Prevent Therapeu Medicine. 2014;2(1):10-4.

16. Yalynkaya A, Ozcan Y, Yayla M, Erdemoolu M, Kale A, Akdeniz N. Perinatal J. 2005;13(4):213-7.

Cite this article as: Singh L, Trivedi K. Study of maternal and fetal outcome in twin pregnancy. Int $\mathbf{J}$ Reprod Contracept Obstet Gynecol 2017;6:2272-8. 